\title{
Isotopic Tracing of Fuel Components in Particulate Emissions from Diesel Engines using Accelerator Mass Spectrometry (AMS)
}

Bruce A. Buchholz, Charles J. Mueller, and John Garbak

\section{August 2, 2001}

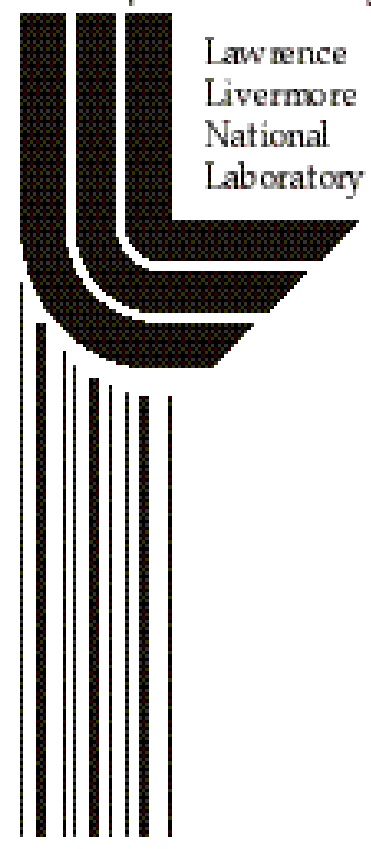




\section{DISCLAIMER}

This document was prepared as an account of work sponsored by an agency of the United States Government. Neither the United States Government nor the University of California nor any of their employees, makes any warranty, express or implied, or assumes any legal liability or responsibility for the accuracy, completeness, or usefulness of any information, apparatus, product, or process disclosed, or represents that its use would not infringe privately owned rights. Reference herein to any specific commercial product, process, or service by trade name, trademark, manufacturer, or otherwise, does not necessarily constitute or imply its endorsement, recommendation, or favoring by the United States Government or the University of California. The views and opinions of authors expressed herein do not necessarily state or reflect those of the United States Government or the University of California, and shall not be used for advertising or product endorsement purposes.

This work was performed under the auspices of the U. S. Department of Energy by the University of California, Lawrence Livermore National Laboratory under Contract No. W-7405-Eng-48.

This report has been reproduced directly from the best available copy.

Available to DOE and DOE contractors from the

Office of Scientific and Technical Information

P.O. Box 62, Oak Ridge, TN 37831

Prices available from (423) 576-8401

http://apollo.osti.gov/bridge/

Available to the public from the National Technical Information Service

U.S. Department of Commerce 5285 Port Royal Rd., Springfield, VA 22161

http://www.ntis.gov/

OR

Lawrence Livermore National Laboratory Technical Information Department's Digital Library http://www.llnl.gov/tid/Library.html 


\section{Isotopic Tracing of Fuel Components in Particulate Emissions from Diesel Engines Using Accelerator Mass Spectrometry (AMS)}

Bruce A. Buchholz (primary contact)

Center for Accelerator Mass Spectrometry, L397

Lawrence Livermore National Laboratory

P.O. Box 808

Livermore, CA 94551

(925) 422-1739; FAX: (925) 423-7884; email: buchholz2@1lnl.gov

Charles J. Mueller

Combustion Research Facility

Sandia National Laboratory

Livermore, CA 94551

DOE Program Manager: John Garbak (202) 586 1723, fax: (202) 586 9811, e-mail:

John.Garbak@ee.doe.gov

DOE contract number W-7405-Eng-48

Objectives

- Determine contribution of diesel fuel components and oxygenates to soot formation.

- Separate volatile and non-volatile fractions of soot.

- Test combustion paradigm that all carbon and oxygen in fuel is equal.

- Produce data to validate combustion modeling.

Approach

- Construct filter assembly to collect exhaust soot.

- Analyze carbon isotope content of all fuel components and lubrication oil.

- Collect soot from skip fired 1.7L optical engine. Complete isotopic analyses of soot and determine contributions from available carbon sources.

Accomplishments

- Filter assembly constructed and in use.

- Preliminary tests completed to determine engine operation conditions for loading filters with sufficient soot for isotopic analyses.

- Determined lubrication oil leakage to be major contributor of carbon emissions from test engine. 
Future Directions

- Determine contributions of major fuel components to soot production and test selected oxygenates.

- Collect gaseous emissions and separate major components.

- Obtain carbon-14 labeled lube oil and run it in conventional diesel engine. Determine contribution of lube oil to soot and $\mathrm{CO}_{2}$ emissions.

- Apply tracing techniques to HCCI (homogeneously charged compression ignition) engines.

\section{Introduction}

Accelerator mass spectrometry (AMS) is an isotope-ratio measurement technique developed in the late 1970s for tracing long-lived radioisotopes (e.g., ${ }^{14} \mathrm{C}$ half life $=5760 \mathrm{y}$ ). The technique counts individual nuclei rather than waiting for their radioactive decay, allowing measurement of more than 100 low-level ${ }^{14} \mathrm{C}$ samples per day (Vogel et al, 1995). The LLNL AMS system is shown in Fig.1.

The contemporary quantity of ${ }^{14} \mathrm{C}$ in living things $\left({ }^{14} \mathrm{C} / \mathrm{C}=1.2 \times 10^{-12}\right.$ or $\left.110 \mathrm{fmol}{ }^{14} \mathrm{C} / \mathrm{g} \mathrm{C}\right)$ is highly elevated compared to the quantity of ${ }^{14} \mathrm{C}$ in petroleum-derived products. This isotopic elevation is sufficient to trace the fate of bio-derived fuel components in the emissions of an engine without the use of radioactive materials. If synthesis of a fuel component from biologically-derived source material is not feasible, another approach is to purchase ${ }^{14} \mathrm{C}$-labeled material (e.g., dibutyl maleate (DBM)) and dilute it with petroleum-derived material to yield a contemporary level of ${ }^{14} \mathrm{C}$. In each case, the virtual absence of ${ }^{14} \mathrm{C}$ in petroleum based fuels gives a very low ${ }^{14} \mathrm{C}$ background that makes this approach to tracing fuel components practical.

Regulatory pressure to significantly reduce the particulate emissions from diesel engines is driving research into understanding mechanisms of soot formation. If mechanisms are understood, then combustion modeling can be used to evaluate possible changes in fuel formulation and suggest possible fuel components that can improve combustion and reduce PM emissions. The combustion paradigm assumes that large molecules break down into small components and then build up again during soot formation. AMS allows us to label specific fuel components, including oxygenates, trace the carbon atoms, and test this combustion modeling paradigm.

Volatile and non-volatile organic fractions (VOF, NVOF) in the PM can be further separated. The VOF of the PM can be oxidized with catalysts in the exhaust stream to further decrease PM. The effectiveness of exhaust stream catalysts to oxidize products from tracer fuel components can be monitored through AMS measurement of carbon in PM.

Approach

The ${ }^{14} \mathrm{C}$ concentration of all fuel components and the lubrication oil were checked by AMS and confirmed to be of petroleum origin $\left({ }^{14} \mathrm{C} / \mathrm{C}\right.$ ratios $\left.\sim 10^{-15}\right)$. A test fuel containing $88 \% \mathrm{DBM}, 7 \% \mathrm{n}-$ hexadecane (NHD) and 5\% ethylhexyl nitrate (EHN) was spiked with labeled DBM to obtain fuel containing $78 \mathrm{fmol}{ }^{14} \mathrm{C} / \mathrm{g} \mathrm{C}$, approximately $70 \%$ the ${ }^{14} \mathrm{C}$ found in living things. 
Pre-combusted quartz filters were loaded with PM drawn from the exhaust manifold of a moderntechnology, 4-stroke, heavy-duty DI diesel engine that has been modified to provide extensive optical access into the combustion chamber. Injection timing was optimized such that the engine produced maximum gross indicated torque. The engine operated at 1200-rpm and moderate load (8.00 bar gross indicated mean effective pressure (gIMEP)). The optical engine run in skip fire mode (fire every $12^{\text {th }}$ cycle) required 48 fires to deposit sufficient soot for isotopic analysis (see figure 2). Filters were handled with stainless steel forceps and placed on aluminum foil after loading to avoid contamination with other carbon sources.

Some filters were baked at $340^{\circ} \mathrm{C}$ for $2 \mathrm{~h}$ to remove the VOF of soot. The remaining carbon on the filters was assumed to be NVOF. The procedure was developed using NIST SRM 2975 diesel soot to obtain consistent isotope ratios and mass fraction of the NVOF. SRM 2975 has a 7\% VOF with this procedure. We expect a similar VOF from the optical engine since the soot is collected close to the exhaust manifold without using a dilution tunnel.

\section{Results}

All filters were loaded with a significant amount of carbon. We found lubrication oil deposition on the filters to be a major component of the carbon inventory. The lube oil deposition decreased over the course of a day, but the total carbon remained significant on filters collected with motored cycles only (see Fig. 3). The mass of carbon on filters collected with skip fires was no higher than those with motored cycles only.

The ${ }^{14} \mathrm{C}$ content of the motored and skip fired samples is almost identical. Although the ${ }^{14} \mathrm{C}$ concentration in the fuel is $\sim 1000 \mathrm{x}$ that of the lube oil, the carbon mass on the filters is almost entirely due to lube oil. Removing the VOF from the filters produced a consistent carbon mass (Fig. 3), but the isotope content varied by a factor of six. The heating procedure to remove the VOF did not visibly reduce the deposited soot, indicating the non-combusted lube oil was substantially removed.

\section{Conclusions}

The large contribution of lubrication oil to the exhaust emissions, both as oil from non-fired cycles and as combusted soot, complicates quantitation of fuel components in PM. Results indicate that DBM contributes very little carbon to soot formation in this engine. It is impossible to separate the contributions of the other fuel components, NHD and EHN, from the lube oil due to their similar isotopic signatures. The lube oil signal needs to be reduced either by limiting leakage down the valves and into the cylinder or by removing non-combusted oil as part of sample pretreatment. The logical next step is to obtain labeled lubrication oil for use in this and a conventional engine and determine its contribution to PM emissions. Determining the contribution of lube oil to emissions is important for assessing viability of exhaust catalyst technology.

\section{Reference}

Vogel, J. S.; Turtletaub, K. W.; Finkel, R.; Nelson, D. E. (1995) Accelerator Mass Spectrometry Isotope Quantification at Attomole Sensitivity. Anal. Chem. 67, 353-9A. This work was performed 
in part under the auspices of the U.S. Department of Energy by University of California, Lawrence Livermore National Laboratory under Contract No. W-7405-Eng-48.

FY 2001 Presentation

Bruce Buchholz, Chuck Mueller, and Glen Martin. Isotopic Tracing of Fuel Components in Particulate Emissions from Diesel Engines Using Accelerator Mass Spectrometry. DOE 2001 Review of OTT CIDI Engine Combustion, Emission Control, \& Fuels R\&D National Laboratory Program, Oak Ridge, TN, June 11-13, 2001.

Acronyms

${ }^{14} \mathrm{C}$

AMS

DI

EHN

gIMEP

HCCI

NIST

NHD

NVOF

PM

SRM

VOF carbon-14

accelerator mass spectrometry

direct injection

ethylhexyl nitrate

gross indicated mean effective pressure

homogeneously charged compression ignition

National Institute of Standards and Technology

normal hexadecane

non-volatile organic fraction

particulate matter

standard reference material

volatile organic fraction 
Fig. 1. View of LLNL AMS system from above the high energy magnets. The shared facility annually measures $10,000{ }^{14} \mathrm{C}$ samples at precision to $0.8 \%$ and ${ }^{14} \mathrm{C} / \mathrm{C}$ ratios as low as 1 part in $10^{15}$.

Fig. 2 Quartz filters loaded with emissions from optical engine. The filters were loaded with the following engine operating conditions: (A) motored only without firing, $12 \times 48$ cycles, $0.2 \mathrm{mg} \mathrm{C}$ from lube oil; (B) motored with 48 skip fires, 12x48 cycles, $0.28 \mathrm{mg}$ C from lube oil and soot; (C) motored with 96 skip fires, $2 \times 12 \times 48$ cycles, $0.61 \mathrm{mg} \mathrm{C}$ from lube oil and soot.

Fig. 3 Carbon mass deposited on motored (M) and skip fired (F) filters during a day of operation. The filters are listed on the $\mathrm{x}$-axis in the order in which they were collected. The mass of carbon was normalized to $12 \times 48$ cycles for samples with different collection times. The NVOF carbon mass appeared to be consistent, suggesting the lube oil departed in the VOF. 


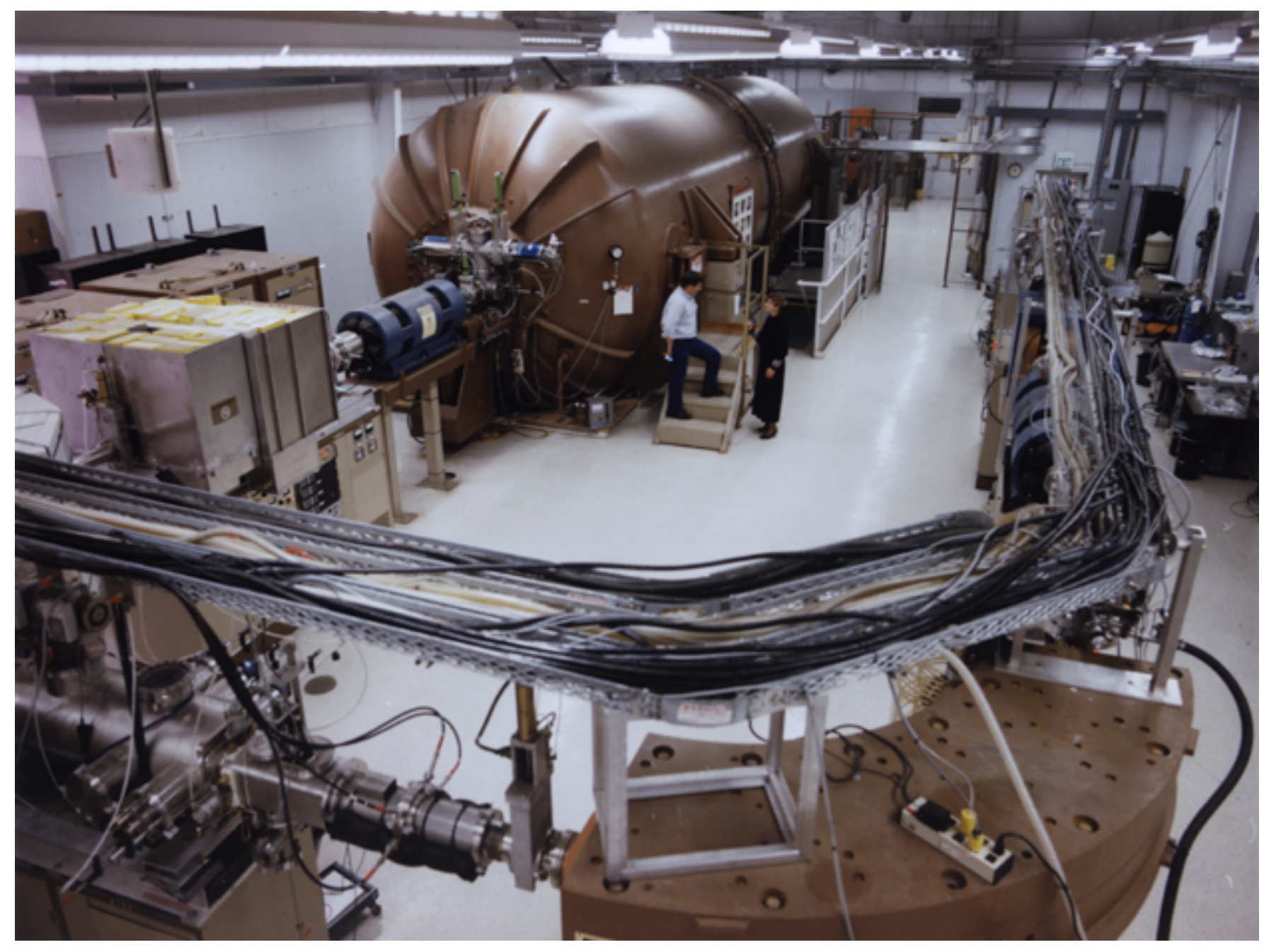




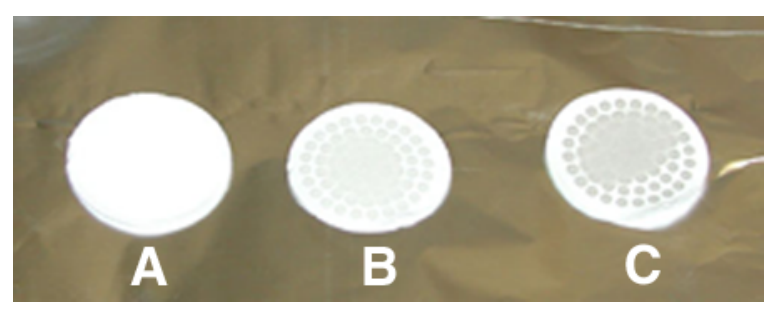




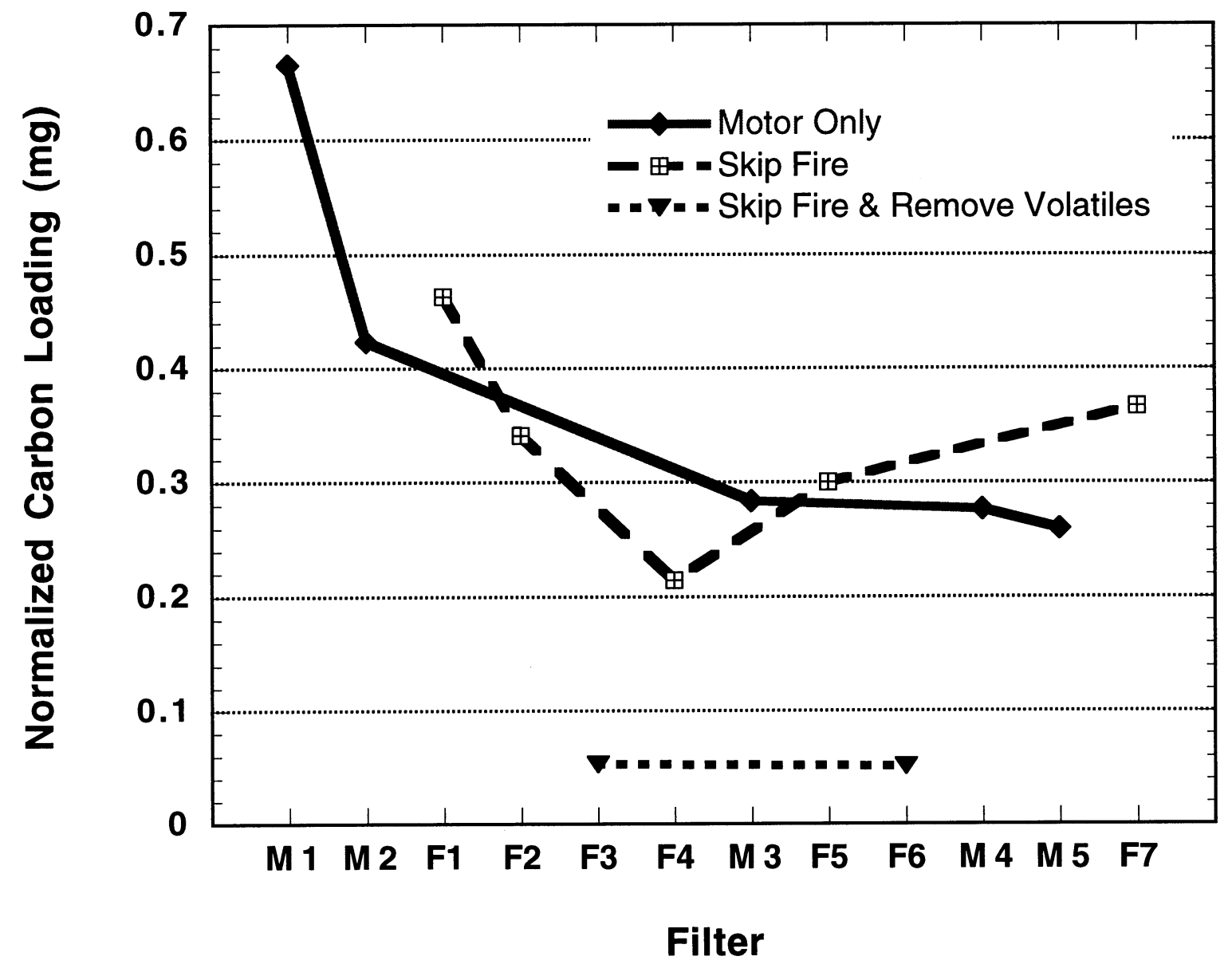

